\title{
Long-term results of the modified Konno procedure in high-risk children with obstructive hypertrophic cardiomyopathy
}

\author{
Mikael Laredo, MD, ${ }^{\mathrm{a}}$ Diala Khraiche, MD, ${ }^{\mathrm{a}}$ Olivier Raisky, MD, ${ }^{\mathrm{a}}$ Régis Gaudin, MD, ${ }^{\mathrm{a}}$ \\ Fanny Bajolle, MD, PhD, ${ }^{a}$ Alice Maltret, $\mathrm{MD},{ }^{\mathrm{a}}$ Sylvie Chevret, $\mathrm{MD}, \mathrm{PhD}$, \\ Damien Bonnet, $\mathrm{MD}, \mathrm{PhD},{ }^{\mathrm{a}}$ and Pascal R. Vouhé, $\mathrm{MD}, \mathrm{PhD}^{\mathrm{a}}$
}

\section{ABSTRACT}

Objective: Transaortic septal myectomy is the gold standard surgery in obstructive hypertrophic cardiomyopathy, but it is not optimal for children aged less than 5 years and with right ventricular outflow tract obstruction. We evaluated outcomes with the modified Konno procedure in children with severe forms of obstructive hypertrophic cardiomyopathy.

Methods: A total of 79 consecutive children who underwent the modified Konno procedure in our center between 1991 and 2016 were included.

Results: Clinical features included age less than 5 years (38\%), maximal septal thickness $25 \mathrm{~mm}$ or more (32\%), extension to the left ventricular apex $(29 \%)$, and right ventricular outflow tract obstruction (28\%). In total, $25 \%$ of patients had Noonan syndrome. Five children $(6 \%)$ aged less than 15 months with Noonan syndrome and biventricular obstruction died in the hospital. Mean follow-up was $6 \pm 5.7$ years. Survival without death and heart transplantation was $82 \%$ at 20 years. Atrioventricular block occurred in 9 patients $(11 \%)$ and was associated with right ventricular outflow tract obstruction and surgery before 2010. Death, resuscitated sudden cardiac death, and appropriate implantable defibrillator shock were associated with maximal septal thickness before surgery (adjusted odds ratio, 1.20; 95\% confidence interval, 1.07-1.35; $P=.002$ ) and need for an associated procedure (adjusted odds ratio, 8.84; $95 \%$ confidence interval, 2.01-38.93; $P=.004$ ). There was no case of recurrent obstruction. Reoperation was required in 4 patients $(5 \%)$ for other reasons.

Conclusions: The modified Konno procedure provided durable obstruction relief and good long-term survival in children with severe forms of obstructive hypertrophic cardiomyopathy. Children with Noonan syndrome undergoing surgery early in life were at higher risk of early mortality. (J Thorac Cardiovasc Surg 2018;156:2285-94)

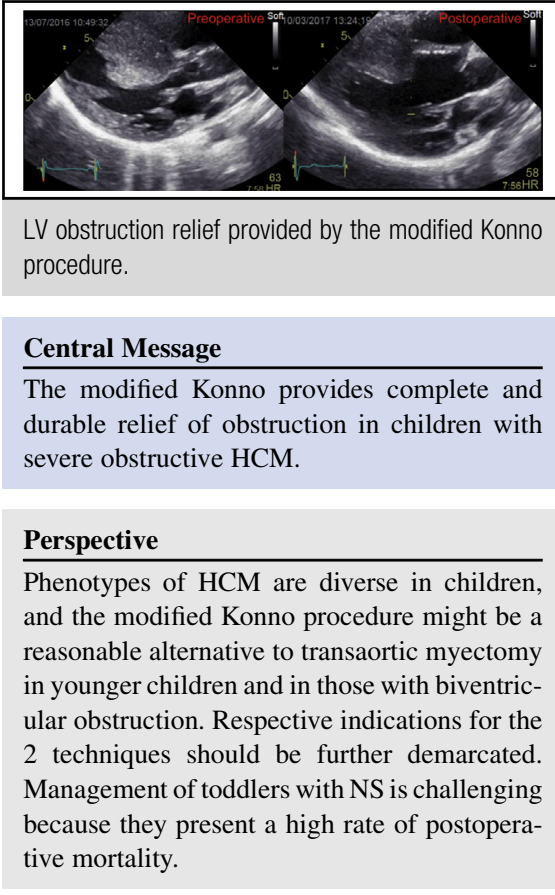

See Editorial Commentary page 2295.

See Editorial page 2283.

\footnotetext{
From the ${ }^{a}$ Unité Médico-Chirurgicale de Cardiologie Congénitale et Pédiatrique, Centre de référence des Malformations Cardiaques Congénitales Complexes-M3C, Hôpital Necker Enfants Malades, APHP, Université Paris Descartes, and ${ }^{\text {b Service }}$ de Biostatistique et Information Médicale, Hôpital Saint Louis, APHP, Université Paris Diderot, Sorbonne Paris-Cité, Paris, France.

This work was supported by an unrestricted grant from the Fondation Coeur et Artères (www.fondacoeur.com).

D.B. and P.R.V. contributed equally.

Received for publication Oct 20, 2017; revisions received June 4, 2018; accepted for publication June 11, 2018; available ahead of print Aug 10, 2018.

Address for reprints: Mikael Laredo, MD, Hôpital Universitaire Necker Enfants Malades, Centre de référence Malformations Cardiaques Congénitales Complexes-M3C, 149 Rue de Sèvres, 75015 Paris, France (E-mail: mik.laredo@ gmail.com).

$0022-5223 / \$ 36.00$

Copyright (c) 2018 by The American Association for Thoracic Surgery

https://doi.org/10.1016/j.jtcvs.2018.06.040
}

The overall long-term prognosis of children with hypertrophic cardiomyopathy (HCM) is good, ${ }^{1-4}$ but the presence of symptomatic left ventricular outflow tract (LVOT) obstruction is a severe condition associated with high mortality and often unresponsive to medical therapy. ${ }^{5}$ Surgical relief of LVOT obstruction benefits long-term

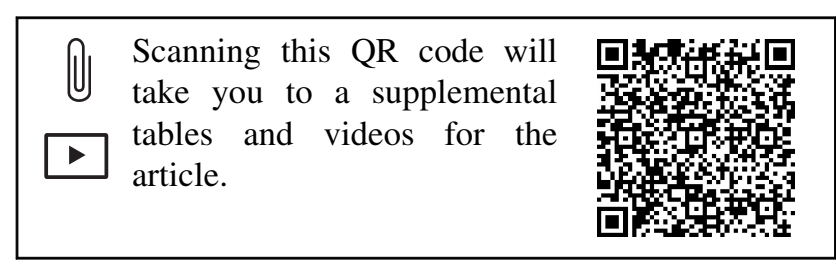




$$
\begin{aligned}
& \text { Abbreviations and Acronyms } \\
& \text { CAVB = complete atrioventricular block } \\
& \mathrm{CI}=\text { confidence interval } \\
& \text { HCM = hypertrophic cardiomyopathy } \\
& \text { ICD = implantable cardioverter-defibrillator } \\
& \mathrm{LV} \quad=\text { left ventricular } \\
& \text { LVH = left ventricular hypertrophy } \\
& \text { LVOT }=\text { left ventricular outflow tract } \\
& \text { NS }=\text { Noonan syndrome } \\
& \text { NYHA }=\text { New York Heart Association } \\
& \mathrm{OR}=\text { odds ratio } \\
& \text { RVOT }=\text { right ventricular outflow tract } \\
& \text { SCD = sudden cardiac death } \\
& \mathrm{TSM}=\text { transaortic septal myectomy }
\end{aligned}
$$

survival and is therefore the common treatment for symptomatic children with LVOT obstruction. ${ }^{6-8}$ Transaortic septal myectomy (TSM) provides excellent results in grown children and adults with isolated LVOT obstruction, ${ }^{6,9}$ but it is more challenging in smaller children because of the small size of the aortic annulus, with risk of LVOT obstruction recurrence and aortic valve injury. ${ }^{7,9,10}$ Also, TSM alone does not address associated right ventricular outflow tract (RVOT) obstruction.

Causes of pediatric HCM are numerous, accounting for a great heterogeneity of anatomic and clinical features. ${ }^{4}$ In Noonan syndrome (NS), a common cause of HCM in children and associated with worse prognosis, HCM is frequently associated with mitral valve malformations and RVOT obstruction. ${ }^{11,12}$ These associated lesions often need to be specifically addressed along with the relief of the LVOT obstruction.

Although TSM is the gold standard treatment for most children with obstructive HCM, alternative techniques might be useful in high-risk patients with specific anatomic or clinical features. The modified Konno procedure, originally designed for complex LVOT stenosis, ${ }^{13,14}$ is a basal septectomy performed through the right ventricle and the aortic orifice, allowing for wide exposure of the LVOT and mitral valve, and facilitating concomitant RVOT obstruction relief. The modified Konno was first performed in our center to address LVOT obstruction recurrences after TSM, which was frequent in younger children. ${ }^{15}$

We evaluated long-term outcomes after the modified Konno procedure in a population of children with severe and extensive obstructive HCM, with frequent associated lesions and biventricular obstruction.

\section{MATERIALS AND METHODS \\ Patients}

We retrospectively included 79 consecutive patients aged 1 month to 18 years who underwent the modified Konno procedure for severe obstructive HCM between 1991 and 2016 at our institution. All patients were symptomatic at presentation and had LVOT obstruction. Children with secondary left ventricular hypertrophy (LVH) related to LVOT or valvular aortic stenosis were excluded. All forms of HCM were included, regardless of the etiology, presence of RVOT obstruction, or associated lesions including mitral valve anomalies. Since 2010, indications for concomitant placement of an epicardial implantable cardioverterdefibrillator (ICD) were systematically discussed, relying on sudden cardiac death (SCD) risk assessment models in pediatric HCM. ${ }^{1,3,16}$ Primary care pediatric cardiologists provided follow-up with echocardiography, exercise test, and 24-hour Holter-electrocardiogram monitoring.

\section{Surgical Technique}

The modified Konno procedure was performed as described previously. ${ }^{14,15}$ The main steps of the modified Konno procedure are shown in Video 1. After median sternotomy, conventional cardiopulmonary bypass was instituted. Myocardial protection was achieved with multidose warm blood cardioplegia. A diagonal incision was made in the aorta, deep into the noncoronary sinus, to gain maximal exposure of the aortic valve and subaortic area. The right ventricular infundibulum was opened transversely below the pulmonary valve. Through the aortic orifice, the top of the subaortic obstruction was incised. A right-angle instrument was introduced in this incision and used to perforate the conal septum, thus providing a landmark for the upper limit of the septal incision away from the aortic cusps. The conal septum was incised downward, remaining away from the conduction tissue. The myectomy was performed on both sides of the septal incision; on the inferior (right-handed) side, resection was limited to the distal part to avoid injuring the conduction tissue. After adequate myectomy, the mitral valve was fully exposed and inspected; associated anomalies of the subvalvar apparatus were addressed (excision of abnormal chordal septal attachments, division of an anomalous papillary muscle inserted on the anterior mitral leaflet) through the right ventriculotomy. Left atriotomy was performed only when access to the mitral valve was required to perform the Alfieri technique in case of mitral regurgitation due to annular dilatation $(\mathrm{n}=1)$ or the retention plasty for severe persistent systolic anterior movement despite mitral valve subvalvular plasty $(\mathrm{n}=1) .{ }^{17,18}$ The septal incision was closed with a polytetrafluoroethylene patch. The right ventricular infundibulum was closed with a pericardial patch, allowing for RVOT enlargement. Additional RVOT muscular resection was performed only in case of biventricular involvement with RVOT obstruction thought to persist despite the right ventricular patch. The aortotomy was sutured. Transesophageal echocardiography was

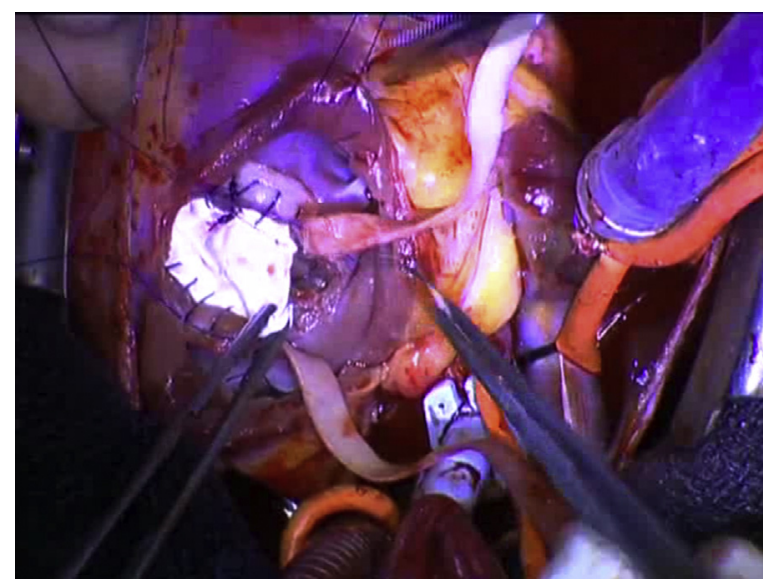

VIDEO 1. Operative video of the modified Konno procedure. Video available at: https://www.jtcvs.org/article/S0022-5223(18)31785-9/fulltext. 
systematically performed before cardiopulmonary bypass weaning to assess residual obstruction, mitral regurgitation, or systolic anterior movement and aortic valve damage.

Since 2010, to reduce the incidence of postoperative atrioventricular block (AVB), particular attention was given to avoid resection of the basal part of the septum on the left side of the septal incision.

\section{Echocardiography}

Echocardiography was performed with routine instruments available at our institution. Relevant data were extracted from reports up to 2004. Beyond that point, offline echocardiographic reviews were performed. Maximal septal thickness was measured in diastole on a 2-dimensional short-axis parasternal view. Maximal LVOT gradient was measured at rest with continuous Doppler and during a Valsalva maneuver when possible. LVOT obstruction was defined as maximal LVOT gradient $40 \mathrm{~mm} \mathrm{Hg}$ or greater.

\section{Statistical Analysis}

For unpaired data, differences in means or median between independent groups were analyzed by $t$ test, Mann-Whitney, or exact Fischer test depending on the type and distribution of the variable. For comparisons between baseline and follow-up, the paired $t$ test, Wilcoxon signed-rank, or McNemar tests were used. Survival was estimated by the Kaplan-Meier method, with comparisons based on the log-rank test. Univariate and multivariate analyses were performed with the Cox proportional-hazards model. Multivariate analyses included variables with $P$ less than .10 on univariate analyses. All tests were 2 -sided. All statistical analyses were performed with IBM SPSS Statistics for MacOS, v23 (IBM Corp, Armonk, NY). Our institutional review board approved the present study (2016-DK-12).

\section{RESULTS \\ Patient Characteristics}

HCM was diagnosed at a median patient age of 6 months. The diagnosis was antenatal in 5 children $(6 \%)$. A total of 57 patients $(72 \%)$ were male. Median age and weight at surgery were 8 years (1.2 month to 19.1 years) and $25.5 \mathrm{~kg}$ (3.6-92), respectively. The mean body surface was $1.1 \pm 0.44 \mathrm{~m}^{2}$. Some $38 \%$ of patients underwent surgery at less than 5 years of age, and 9 patients (11\%) were aged 1 year (Figure 1, A). Causes of HCM are shown in Figure 1, $B$. History of resuscitated cardiac death with cardioverter-defibrillator implantation was present in 4 patients (5\%). A total of 69 patients $(87 \%)$ were receiving beta-blocker therapy. A total of 71 patients $(90 \%)$ were in New York Heart Association (NYHA) class II to IV. Angina pectoris, history of syncope, and congestive heart failure were present in 13 patients $(16 \%), 5$ patients $(6 \%)$, and 5 patients $(6 \%)$, respectively. Among the 29 patients undergoing operation at less than 5 years of age, 5 infants with NS and biventricular obstruction had overt heart failure, $22(76 \%)$, including the 9 infants undergoing operation at less than 1 year of age had severe growth impairment, and all were in NYHA class II to IV (Table 1). At rest, LVOT obstruction was present in 74 patients $(94 \%)$. Severe LVH with subaortic septal
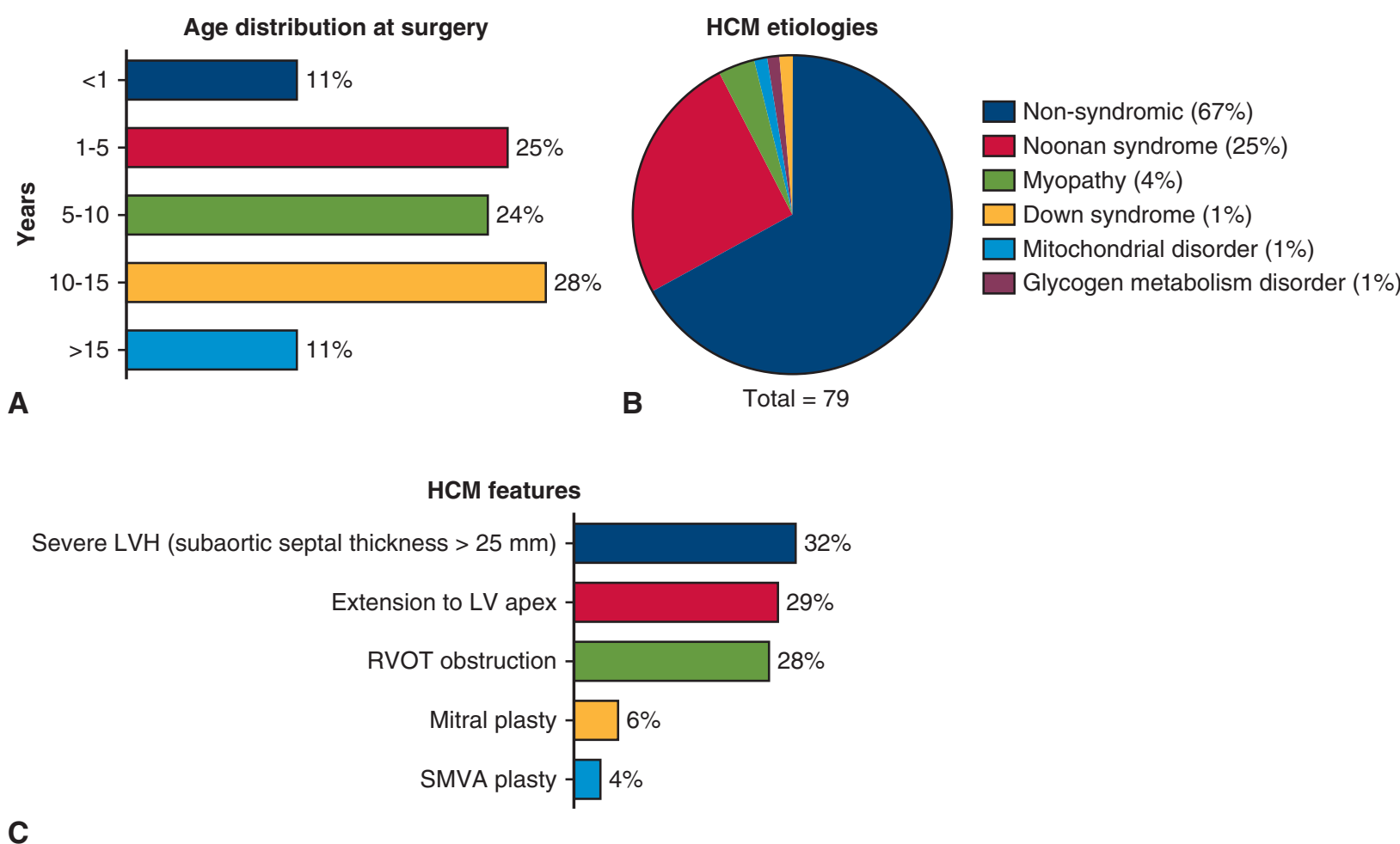

FIGURE 1. Patient characteristics. A, Distribution of age at the time of surgery. B, HCM causes. Secondary forms accounted for $33 \%$ of the population. C, Anatomic features. HCM, Hypertrophic cardiomyopathy; $L V H$, left ventricular hypertrophy; $L V$, left ventricle; $R V O T$, right ventricular outflow tract; SMVA, subvalvular mitral valve apparatus. 
TABLE 1. Characteristics of patients according to their age group $(n=79$ patients $)$

\begin{tabular}{|c|c|c|c|c|}
\hline & $<5$ y $(n=29)$ & $5-10$ y $(n=19)$ & $10-15$ y $(n=22)$ & $>15$ y $(n=9)$ \\
\hline Surgery before age $1 \mathrm{y}$ & $9(31)$ & - & - & - \\
\hline Nonsyndromic HCM & $17(59)$ & $15(79)$ & $15(68)$ & $6(67)$ \\
\hline NS & $12(41)$ & $4(21)$ & $3(14)$ & $1(11)$ \\
\hline Maximal septal thickness (mm) & $16.8 \pm 5.7$ & $24.7 \pm 6.3$ & $27 \pm 5.7$ & $32(19-40)$ \\
\hline Maximal septal thickness z-score & $+16.6(+8-+38.1)$ & $+18.2(+9.5-+23.8)$ & $+16.7(+10-+30.2)$ & $+19.2(+9.9-+28.7)$ \\
\hline Maximal LVOT gradient $(\mathrm{mm} \mathrm{Hg})$ & $83(45-196)$ & $92(38-165)$ & $100(36-237)$ & $113(95-144)$ \\
\hline Right ventricular involvement & $10(34)$ & $4(21)$ & $7(32)$ & $2(22)$ \\
\hline RVOT obstruction & $12(41)$ & $4(21)$ & $6(27)$ & 0 \\
\hline Mitral valve dysplasia & $6(21)$ & $4(21)$ & 0 & 0 \\
\hline Anomalous SMVA & $7(24)$ & $4(21)$ & $3(14)$ & $1(11)$ \\
\hline \multicolumn{5}{|l|}{ Mitral regurgitation } \\
\hline Mild & $5(17)$ & $6(32)$ & $7(32)$ & $1(11)$ \\
\hline Moderate or severe & $7(24)$ & $1(5)$ & $3(14)$ & 0 \\
\hline
\end{tabular}

Data are $\mathrm{n}(\%)$, median (range) or mean \pm standard deviation (SD). HCM, Hypertrophic cardiomyopathy; NS, Noonan syndrome; LVOT, left ventricular outflow tract; RVOT, right ventricular outflow tract; SMVA, subvalvular mitral valve apparatus.

thickness greater than $25 \mathrm{~mm}$, associated RVOT obstruction, and mitral valve abnormalities were frequent (Figure 1, C). Among the 22 children (28\%) with associated RVOT obstruction, 10 had NS. Patients aged less than 5 years had frequent associated cardiac lesions and secondary forms (Table 1).

\section{Procedural and Early Outcomes}

An epicardial ICD was implanted in 15 patients (19\%) considered at high risk on preoperative risk assessment. A concomitant procedure was performed in 15 patients (19\%), including 8 RVOT muscular resections for RVOT obstruction or pulmonary valve repairs and 7 mitral valve repairs, including 1 failure leading to mechanical mitral valve replacement. Median inotropic drug use time and median mechanical ventilation time were both less than 1 day (range 0-45 and 0-65 days, respectively). Median intensive care unit and hospital lengths of stay were 3 days (range 0-84) and 10 days (range 5-95), respectively.

Five children $(6 \%)$ died in the intensive care unit because of refractory heart failure due to major biventricular diastolic dysfunction at a median time of 40 days (range, 5-108) after surgery. All had NS and biventricular obstruction, and underwent surgery before age 15 months.

Postoperative complete atrioventricular block (CAVB) occurred in 9 patients $(11 \%)$ and was associated with RVOT obstruction (odds ratio [OR], 4.22; 95\% confidence interval $[\mathrm{CI}], 1.01-15.47 ; P=.04$ ) (Table 2). Age at procedure, weight, and maximal septal thickness were not associated with CAVB. CAVB incidence significantly decreased after 2010 after surgical technique modification (8/33 [24\%] before 2010 and $1 / 37$ [3\%] after 2010, $P=.03$ ) (Figure 2).

\section{Long-Term Outcomes}

Mean follow-up among the 74 hospital survivors was $6.02 \pm 5.7$ years. No patient was lost to follow-up. Cumulative survival without death and transplantation was $100 \%, 96 \%$, and $82 \%$ at 1,5 , and 20 years, respectively (Figure 3, A, 95\% CIs reported in Table E1). There were 3 late deaths at $1.3,3.3$, and 14.3 years after surgery. The first death was due to an acute myocardial infarction several years after surgery in a child who had an intramural right coronary artery and who previously underwent coronary bypass. The second death was due to severe paraprosthetic regurgitation in the child who had mitral valve replacement. The third child died while on the wait list for heart transplantation, with severe heart failure related to diastolic dysfunction. Three patients underwent transplantation for the same reason at 3, 6.4, and 9 years after surgery. Two patients with nonsyndromic HCM experienced SCD from ventricular arrhythmia and were successfully resuscitated. One patient had an appropriate ICD shock for syncopal ventricular tachycardia. No patient had ICD inappropriate shock.

Patients with NS were significantly younger at the time of diagnosis and surgery than those with nonsyndromic HCM and more frequently had RVOT obstruction, pulmonary valvular stenosis, right ventricular involvement, and mitral valve dysplasia (Table E2). Survival without death, including in-hospital mortality, transplantation, resuscitated SCD, and ICD appropriate shock, in NS and nonsyndromic HCM is shown in Figure 3, $B$ (CIs reported in Table E1).

On multivariate analysis, the occurrence of death, transplantation, resuscitated SCD, and ICD appropriate shock among hospital survivors were associated with maximal septal thickness before surgery (adjusted OR 
TABLE 2. Predictors of outcomes after the modified Konno procedure

\begin{tabular}{|c|c|c|c|c|}
\hline \multirow[b]{2}{*}{ Outcomes } & \multicolumn{2}{|c|}{ Univariate analyses } & \multicolumn{2}{|c|}{ Multivariate analysis } \\
\hline & OR $(95 \%$ CI $)$ & $P$ value & OR $(95 \%$ CI) & $P$ value \\
\hline \multicolumn{5}{|l|}{ Postoperative CAVB } \\
\hline RVOT obstruction & $4.22(1.01-15.47)$ & .04 & & \\
\hline \multicolumn{5}{|c|}{$\begin{array}{l}\text { Event-free survival without death, transplantation, } \\
\text { resuscitated sudden cardiac death, and appropriate shock }\end{array}$} \\
\hline Age at diagnosis & $1(0.88-1.20)$ & .7 & & \\
\hline Age at procedure & $0.97(0.86-1.10)$ & .7 & & \\
\hline NS & $0.42(0.05-3.4)$ & .4 & & \\
\hline Maximal septal thickness & $1.16(1.03-1.30)$ & .02 & $1.20(1.07-1.35)$ & .002 \\
\hline Associated lesion* & $3.75(1.01-14.03)$ & .05 & $8.84(2.01-38.93)$ & .004 \\
\hline Right ventricular involvement & $1.95(0.52-7.32)$ & .3 & & \\
\hline \multicolumn{5}{|l|}{ Diastolic dysfunction at last evaluation } \\
\hline Baseline diastolic dysfunction & $0.85(0.31-2.33)$ & .8 & & \\
\hline Preoperative maximal septal thickness & $1.12(1.01-1.21)$ & .04 & & \\
\hline Ventricular pacing & $2.15(0.45-10.31)$ & .3 & & \\
\hline NS & $0.59(0.11-3)$ & .5 & & \\
\hline
\end{tabular}

[for 1-mm increase], 1.20; 95\% CI, 1.07-1.35; $P=.002$ ) and presence of an associated lesion requiring a supplementary procedure (adjusted OR, 8.84; 95\% CI, 2.01-38.93; $P=.004$ ) (Figure $4, A$ and $B$, CIs reported in Table E1). On receiver operating characteristic curve analysis, a maximal septal thickness of $\geq 25 \mathrm{~mm}$ best predicted late events $(\log$-rank $P=.04)$.

Four patients $(5 \%)$ were reoperated for a residual lesion directly related to the modified Konno procedure ( 3 residual ventricular septal defects requiring surgery and 1 iatrogenic aortic valve regurgitation). No LVOT obstruction recurred during follow-up. Finally, 1 patient received mitral mechanical valve replacement for progressive mitral regurgitation 4.35 years after the initial surgery.

At last evaluation, $82 \%$ of patients were in NYHA class I (Figure 5, A). All patients showed complete resolution of LVOT obstruction (Table 3, Videos 2 and 3). Minor right residual gradient was noticed in 2 of 22 patients with initial RVOT obstruction. Three patients had nonsignificant residual ventricular septal defect with peak velocity greater than $4 \mathrm{~m} / \mathrm{s}$. Residual mitral regurgitation was noted in 1 case. Mild aortic valve regurgitation, noted in $18 \%$ of
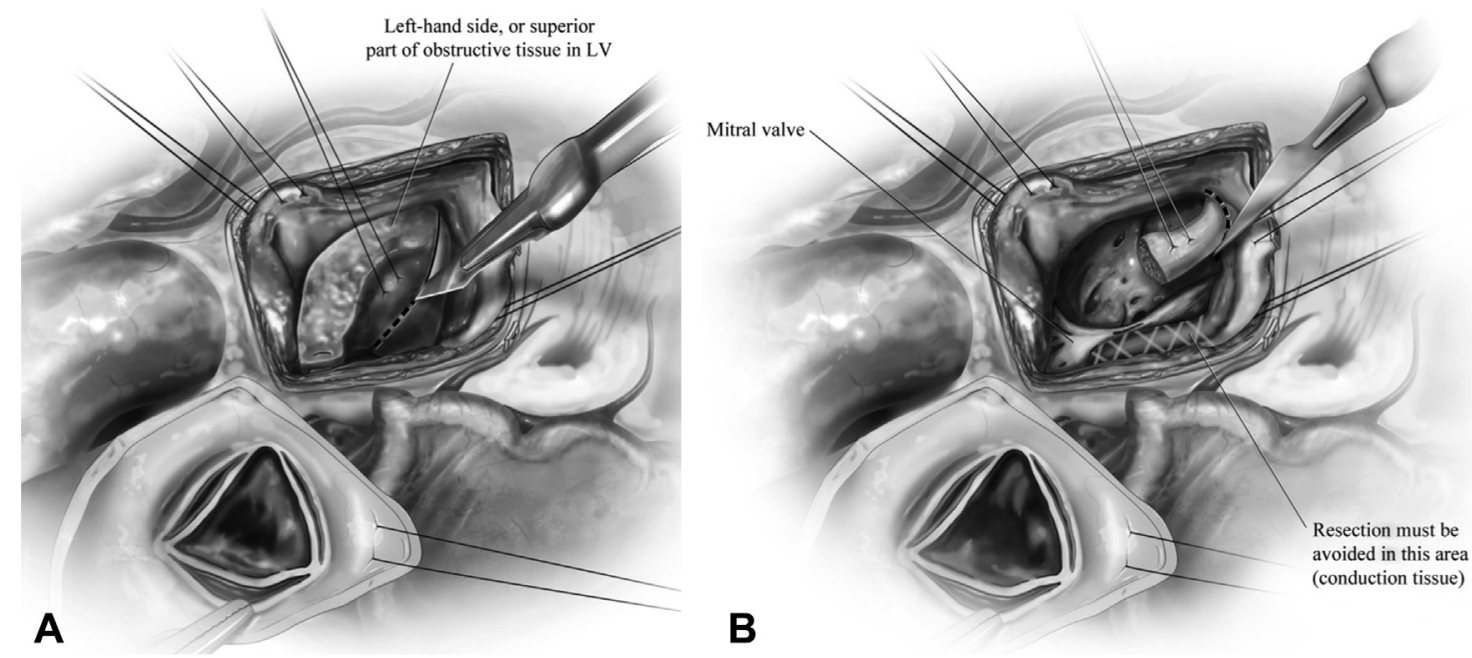

FIGURE 2. A focus on the technique modification associated with a reduction in atrioventricular block occurrence. A, First, extensive septal resection is performed on the superior (left) side by removing the septal tissue in a single piece. B, Septal resection is pursued on the inferior (right) side. Here, it is imperative to limit the resection to the distal part to avoid injury of the conductive tissue (white crosses). From 2010, particular attention was given in avoiding resection of the basal septum on the inferior side of the incision. $L V$, Left ventricle. Images obtained with permission from Vouhé PR. Valve-sparing Konno and hypertrophic obstructive cardiomyopathy in children. Oper Tech Thorac Cardiovasc Surg. 2014;19:164-78. 


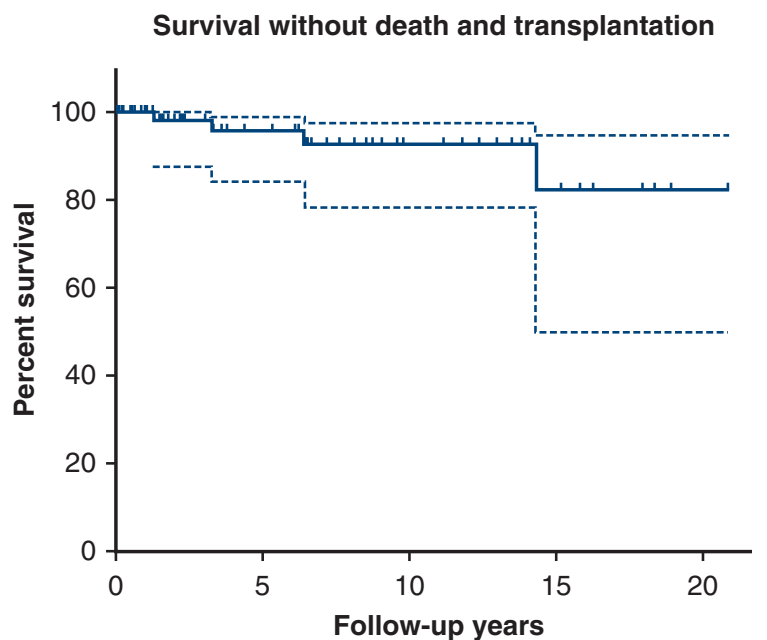

Number at risk:

$74 \quad 33$

A

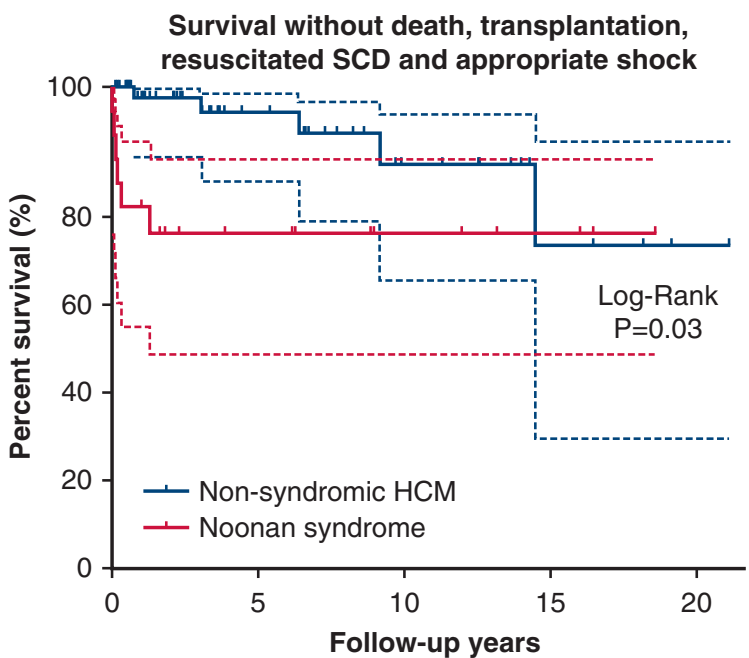

Number at risk:

Non-syndromic HCM: 53

Noonan syndrome: $20 \quad 10$

B

FIGURE 3. Long-term results of the modified Konno procedure among the 74 children discharged alive from hospital. A, Kaplan-Meier representation of survival without reintervention. B, Kaplan-Meier representation of survival without death, heart transplantation, resuscitated SCD, and appropriate shock. Table E1 shows CIs. SCD, Sudden cardiac death; HCM, hypertrophic cardiomyopathy.

patients at baseline, did not progress after surgery and was seen in $24 \%$ of patients at last follow-up.

Noticeably, 6 patients $(8 \%)$ developed congestive heart failure due to left ventricular (LV) diastolic dysfunction with markedly elevated LV filling pressures as estimated by echocardiography and pulmonary pressures, leading to 1 death and 3 heart transplantations. Diastolic dysfunction occurred several years after the operation in each of these cases.

From 2011 onward, concomitant ICD implantation for primary prevention was performed in 20 patients and 16 patients underwent surgery without ICD implantation (Table E3). During a mean follow-up of 3.11 years after ICD implantation, no inappropriate shock or lead-related

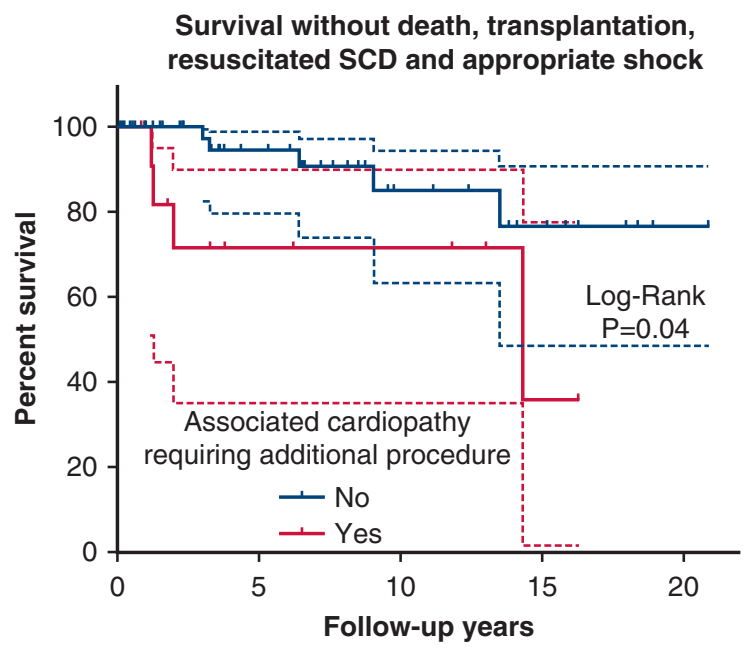

Number at risk:
No: $62 \quad 30$

Yes: 12
14

5

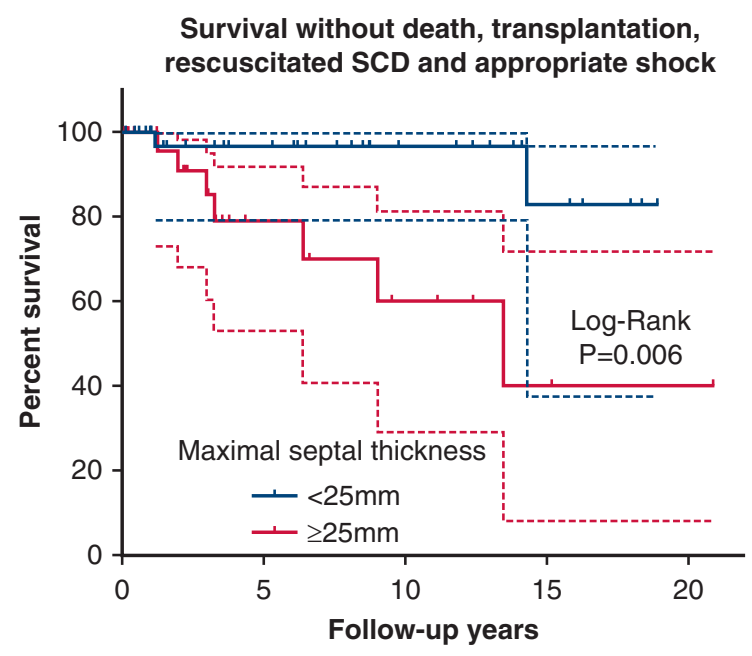

Number at risk:

$\begin{array}{lllcll}<25 \mathrm{~mm}: & 39 & 23 & 13 & 7 & 1 \\ \geq 25 \mathrm{~mm}: & 35 & 10 & 5 & 2 & 1\end{array}$

B

FIGURE 4. Predictors of the long-term results of the modified Konno procedure among the 74 children discharged alive from hospital. A and B, Kaplan-Meier representations of survival without death, heart transplantation, resuscitated SCD, and appropriate shock. Table E1 shows CIs. SCD, Sudden cardiac death. 


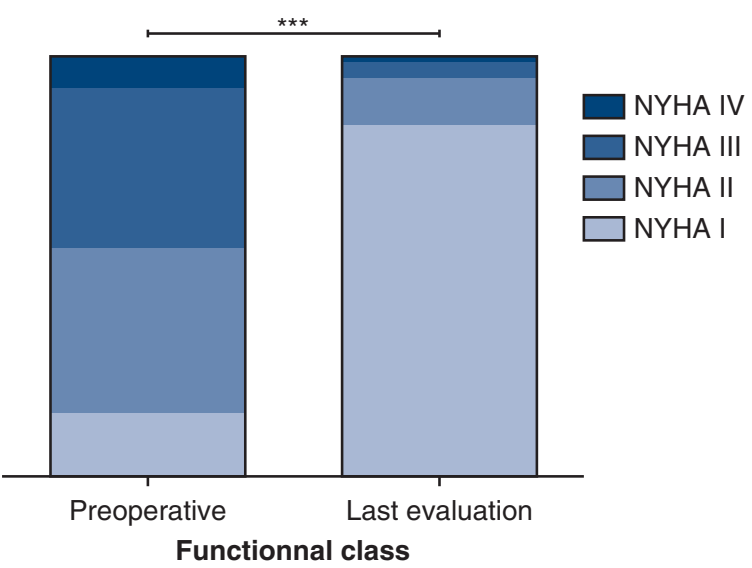

FIGURE 5. NYHA functional classes before surgery and at last evaluation. Preoperative: NYHA I $(\mathrm{n}=7,9 \%)$, II $(\mathrm{n}=25,32 \%)$, III $(\mathrm{n}=30,38 \%)$, IV $(\mathrm{n}=6,8 \%)$. Last evaluation: NYHA I $(\mathrm{n}=55$, $83 \%)$, II ( $\mathrm{n}=9,12 \%)$, III $(\mathrm{n}=3,4 \%)$, IV $(\mathrm{n}=1,1 \%), P<.0001$. NYHA, New York Heart Association.

complication occurred, and 1 patient had an appropriate shock for syncopal ventricular tachycardia. Among patients without implantation, 1 experienced ventricular fibrillation and was successfully resuscitated. This girl, with no family history of HCM, underwent surgery at age 6 years; maximal septal thickness z-score was 11, and 24-hour electrocardiogram and exercise arterial pressure profile were normal.

\section{DISCUSSION}

HCM is the second most frequent form of cardiomyopathy in children and may be associated with a broad range of causes, including sporadic or familial sarcomeric gene mutations, inborn errors of metabolism, neuromuscular disorders, and malformation syndromes. ${ }^{4}$ Asymptomatic children with idiopathic nonobstructive HCM show a favorable outcome-less than $3 \%$ of death or heart transplantation 1 year after diagnosis-whereas children with symptoms and LVOT obstruction managed conservatively show a 10 -year cumulative survival of only $50 \% .^{5}$

TABLE 3. Echocardiographic findings

\begin{tabular}{lccc}
\hline & Preoperative & Last evaluation & $\boldsymbol{P}$ value \\
\hline $\begin{array}{l}\text { Maximal LVOT } \\
\text { gradient (mm Hg) }\end{array}$ & $100(36-237)$ & $11 \pm 6.6$ & $<.0001$ \\
$\begin{array}{l}\text { Maximal LVOT } \\
\text { velocity (m/s) }\end{array}$ & $5 \pm 1.1$ & $1.6 \pm 0.5$ & $<.0001$ \\
RVOT obstruction & $13(16)$ & $2(3)$ & .002 \\
$\begin{array}{l}\text { Mitral regurgitation } \\
\text { Mild }\end{array}$ & $22(28)$ & $1(1)$ & $<.0001$ \\
$\quad \begin{array}{l}\text { Moderate } \\
\text { Severe }\end{array}$ & $13(16)$ & $1(1)$ & .001 \\
\hline
\end{tabular}

Data are $\mathrm{n}(\%)$, median (range), or mean \pm SD. LVOT, Left ventricular outflow tract; RVOT, right ventricular outflow tract.

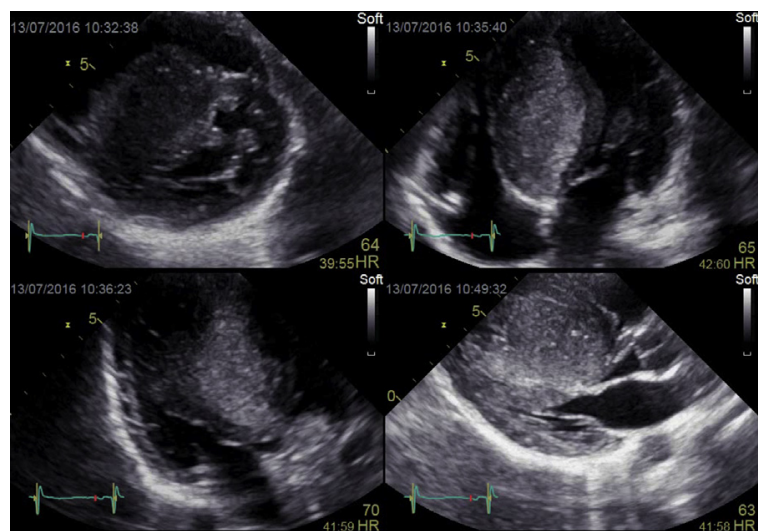

VIDEO 2. Baseline transthoracic echocardiography in a 9-year-old patient referred for the modified Konno procedure. Video available at: https://www.jtcvs.org/article/S0022-5223(18)31785-9/fulltext.

Experience with percutaneous treatments such as alcohol septal reduction or radiofrequency catheter ablation in children is very limited. ${ }^{19,20}$ Therefore, surgery is indicated in children with severe LVOT obstruction despite medical therapy to alleviate symptoms and to improve long-term survival. ${ }^{21}$

TSM is the most commonly performed technique. After TSM, adult patients have a long-term survival comparable to age-matched patients without LVOT obstruction. ${ }^{22,23}$ In children, TSM provides excellent long-term results when performed in experienced centers. ${ }^{6,8}$ The most recent report from Mayo Clinic including 56 children (mean age at surgery, 11 years) described no postoperative death, only 1 pacemaker implantation, and $93 \%$ survival at 10 follow-up years. However, assuming the wide phenotypical diversity of pediatric HCM, TSM may not always be the best solution, and alternative methods may be of interest for selected patients.

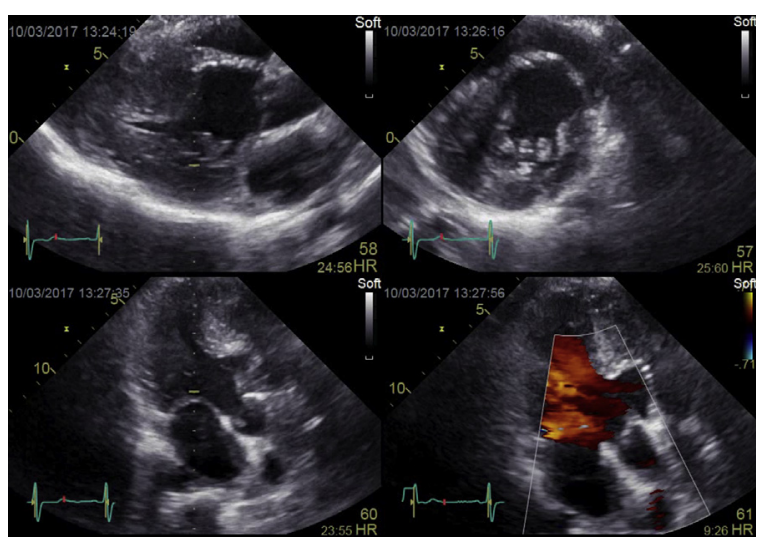

VIDEO 3. Transthoracic echocardiography in the same patient 6 months after the modified Konno procedure. A prosthetic patch replaces the basal segment of the interventricular septum, relieving LVOT obstruction. Video available at: https://www.jtcvs.org/article/S0022-5223(18)31785-9/ fulltext. 
We reported the long-term outcomes of the modified Konno procedure for obstructive HCM in a relatively large cohort of high-risk patients with frequent specific features, such as syndromic forms, RVOT obstruction, mitral valve dysplasia, and very young age. Our main findings are that (1) the modified Konno procedure provided durable and complete obstruction relief even in the youngest children; (2) the incidence of CAVB was significant but was reduced after a technical modification; and (3) the infants with NS and biventricular obstruction had a poor outcome after surgery.

TSM may be challenging in young children because of insufficient visualization of the LV cavity through a small aortic orifice. In their cohort, Minakata and colleagues ${ }^{10}$ reported age 14 years or less to be the only predictor of late reoperation; the rate was $5 \%$ at 5 years. ${ }^{9}$ In general, TSM is considered to be particularly challenging in patients aged less than 5 years, despite no evidence to support this cutoff. Other challenges associated with TSM include a risk of obstruction recurrence related to myocardial growth and progression in $\mathrm{LVH}$, particularly observable during adolescence, ${ }^{24}$ that could reverse the septal reduction provided by myectomy ${ }^{10}$ and a risk of aortic valve injury, with up to $6 \%$ of patients requiring subsequent aortic valve repair. ${ }^{8}$ With the modified Konno procedure, the replacement of the basal septum by a prosthetic patch may be a guarantee of permanent relief of LVOT obstruction. In our series, no patient had recurrent LVOT obstruction, even when surgery was performed in the first years of life. Only 1 child had to undergo reoperation for traumatic aortic valve regurgitation, and we observed no significant progression of preoperative mild aortic regurgitation, although our patients were younger than in previous large series (median age 8 vs 14 years). ${ }^{6,8}$ The modified Konno procedure also ensured relief of associated RVOT obstruction that TSM alone does not address. Associated RVOT obstruction is a rare feature of $\mathrm{HCM}$, and right-side surgery is needed in only $0.5 \%$ in the largest published experience. ${ }^{25}$ However, it is not exceptional in syndromic forms and in NS in particular. ${ }^{4}$ Management of RVOT obstruction is scarcely described in the literature, and patients with RVOT obstruction were excluded from large series reporting the outcomes of $\mathrm{TSM}^{6,8}$ whereas it was present in one fifth of our patients. It has to be noted that a recent small case series reported good results of TSM associated with ventriculotomy in 11 children with biventricular obstruction (6 with NS), ${ }^{25}$ with less mortality than with the modified Konno procedure in our experience. The safety of this approach needs to be confirmed in larger series.

In our study, the incidence of CAVB was dramatically higher than for TSM $(11 \%$ vs $1 \%) .{ }^{6,8}$ In our opinion, this risk is related to the surgery by itself, which includes resection of the basal septum, rather than to the high-risk features of the study population. Concomitant RVOT muscular resection was found to be a risk factor for CAVB, a finding consistent with a recent study addressing TSM with RVOT muscular resection in children with biventricular obstruction, reporting an 18\% CAVB incidence rate, a proportion similar to ours. ${ }^{25}$ Of note, the surgical technique was modified in 2010 to avoid resection of the basal septum of the inferior side of the incision. This revision led to a significant reduction in CAVB occurrence rate, that is, $3 \%$ from 2010 onward.

We report a $6 \%$ rate of postoperative mortality, which exclusively concerned infants aged less than 15 months with NS and biventricular obstruction. These 5 infants with overt heart failure died of severe diastolic dysfunction after surgery. Previous studies have reported high mortality rates in infants with NS-related $\mathrm{HCM},{ }^{11,26}$ and a greater extent of endocardial fibrosis has been found in NS cardiac biopsies compared with age-, gender-, and body surface-matched samples from children with nonsyndromic $\mathrm{HCM}^{27}$ We hypothesize this adverse outcome to be related to a specific phenotype in NS-related HCM characterized by severe biventricular obstruction, congestive heart failure in the first months of life, and diastolic dysfunction exacerbated by surgery. If the high prevalence of associated RVOT obstruction and mitral valve lesions make older patients with NS good candidates for the modified Konno procedure, infants with NS should be regarded as very high risk for the operation. Whether TSM could be safer in these patients is questionable, because postoperative death after TSM in infants with NS has been reported. ${ }^{26}$ Our opinion is that infants with NS should not undergo surgery and rather should be referred for heart transplantation if the resource is available. The development of drugs targeting signaling pathways involved in RASopathies might change the prognosis of infants with NS with severe $\mathrm{HCM}^{28}$ Conversely, children with NS who underwent surgery after 1 year had an overall uneventful long-term follow-up, with no recurrent LVOT obstruction, arrhythmic event, or severe diastolic dysfunction. As reported previously, the long-term cumulative survival tended to be similar for patients with NS and nonsyndromic HCM, with a cumulative event rate in nonsyndromic HCM progressively catching up with the early mortality in NS. ${ }^{11}$

Overall, the morbidity and mortality rates reported in our study favor considering TSM, when performed in high-volume centers, as safer than the modified Konno for most children with obstructive HCM. That being said, one must keep in mind that patients included in TSM series are very different from ours on many points. First, our patients were younger, with one third aged less than 5 years at operation. As stated previously, younger age affects TSM safety and long-term outcomes, as well as the overall HCM-related prognosis. Second, although syndromic forms 
of obstructive HCM were excluded from the large TSM series, they represented $25 \%$ of our population. The poorer prognosis of secondary forms with more frequent associated RVOT and mitral valve anomalies is well known. ${ }^{11,28}$ Third, the frequency of associated cardiac lesions such as RVOT obstruction or mitral valve anomalies requiring a specific additional procedure was high and associated with long-term complications. Thus, the early mortality and long-term complications might be driven to some extent by the high-risk characteristics of our population.

Although the nature of our study does not allow for a direct comparison between TSM and the modified Konno, we believe our work to be helpful to better demarcate their respective indications. In children aged more that 5 years with isolated LVOT obstruction and moderately severe associated lesions, which are the majority of patients, TSM should be preferred. In children aged less than 5 years, with severe LVH, biventricular obstruction, or severe associated mitral valve lesions, we think that the modified Konno may represent a strong alternative to TSM and is favored in our center.

In our study, 6 patients developed severe diastolic dysfunction leading to 1 death and 3 heart transplantations. If obstruction relief may have a positive impact on diastolic function in $\mathrm{HCM},{ }^{29-31}$ diastolic dysfunction may be related to the myocardial disease and some patients may progress toward a restrictive physiology, regardless of LVOT obstruction. ${ }^{30}$ In $8 \%$ of our patients, diastolic dysfunction appeared several years after surgery and was not was associated with any procedural outcomes, including pacemaker implantation, which suggests that this phenomenon was rather related to HCM's natural history. Children with obstructive HCM in whom restrictive physiology develops despite LVOT obstruction relief have a poor prognosis and should be referred for transplantation.

Prophylactic ICD implantation was performed in children with commonly admitted risk factors. ${ }^{16}$ The mean follow-up of patients with ICD was 3.1 years, whereas the time between implantation and the first appropriate therapy has been reported to be 2.9 years, on average, and more than 5 years in $30 \%$ of patients. ${ }^{16}$ Rates of appropriate ICD therapies have been found similar in children with 1 or several risk factors, and a difficulty resides in LVH severity assessment because of the lack of risk models including z-scores of LV thickness. ${ }^{16}$ In our study, a 6-year-old child with no risk factor for SCD except maximal septal thickness of $20 \mathrm{~mm}$ (z-score +10$)$ experienced resuscitated ventricular fibrillation 2 years after surgery. Therefore, our practice evolved toward a wide ICD implantation in children with 1 or more SCD risk factors. A longer follow-up will be needed to assess the impact of the surgery on the incidence of arrhythmic events.

\section{Study Limitations}

We conducted this study in a tertiary center, and the population with severe LVH, frequent RVOT obstruction, and associated lesions may not be representative of the global picture of pediatric obstructive HCM. This study was not designed to directly compare the modified Konno procedure to TSM, and we acknowledge that some our patients might have been potential candidates for TSM instead of the modified Konno. The choice of performing the modified Konno procedure was certainly in some cases influenced by stronger local expertise with the modified Konno than with TSM.

The retrospective nature of the study may reinforce the risk of selection bias. Comparisons of functional status and echocardiographic parameters between the preoperative state and the last evaluation may reflect several years of growth. The small number of patients and events warrant caution in interpreting our regression analyses. Variables associated with in-hospital mortality often coexisted in patients who died after surgery, which precluded multivariate analysis.

\section{CONCLUSIONS}

The modified Konno procedure ensured complete and durable relief of obstruction along with marked functional improvement in children with severe obstructive HCM. Morbidity and mortality were higher than in TSM but occurred mainly in infants with NS for whom the surgical management of severe HCM remains challenging. This technique should be considered as an alternative to TSM with extensive hypertrophy, associated right heart obstruction, and older children with secondary HCM. Longer follow-up is needed to describe the incidence of diastolic dysfunction and arrhythmic events.

\section{Conflict of Interest Statement}

Authors have nothing to disclose with regard to commercial support.

The authors thank Nicolas Garcelon for providing an online database and Claire Boulety for useful guidance. The authors are grateful to the cardiologists of the $\mathrm{M} 3 \mathrm{C}$ network for providing with follow-up data (P. Acar, H. Ansquer, A. Bah, K. Bey, E. Bourges-Petit, L. Cohen, A. Edmar, A. Fraisse, P. Fry, S. Greciano, C. Gronier, T. Hazelzet, L. Iserin, M. Ladouceur, J. Le Bidois, L. Le Gloan, M. Lévy, H. Lucron, JM. Lupoglazoff, J. Martino, P. Mauran, C. Ovaert, J. Radojevic, D. Satsou, D. Stepowski, andG. Vaksmann). The authors also thank the Fondation Coeur et Arteres for supporting this research.

\section{References}

1. Yetman AT, Hamilton RM, Benson LN, McCrindle BW. Long-term outcome and prognostic determinants in children with hypertrophic cardiomyopathy. J Am Coll Cardiol. 1998;32:1943-50.

2. Colan SD, Lipshultz SE, Lowe AM, Sleeper LA, Messere J, Cox GF, et al. Epidemiology and cause-specific outcome of hypertrophic cardiomyopathy in 
children: findings from the pediatric cardiomyopathy registry. Circulation. 2007; 115:773-81.

3. Lipshultz SE, Orav EJ, Wilkinson JD, Towbin JA, Messere JE, Lowe AM, et al. Risk stratification at diagnosis for children with hypertrophic cardiomyopathy: an analysis of data from the pediatric cardiomyopathy registry. Lancet. 2013; 382:1889-97.

4. Moak JP, Kaski JP. Hypertrophic cardiomyopathy in children. Heart Br Card Soc. 2012;98:1044-54.

5. McKenna W, Deanfield J, Faruqui A, England D, Oakley C, Goodwin J. Prognosis in hypertrophic cardiomyopathy: role of age and clinical, electrocardiographic and hemodynamic features. Am J Cardiol. 1981;47:532-8.

6. Minakata K, Dearani JA, O'Leary PW, Danielson GK. Septal myectomy for obstructive hypertrophic cardiomyopathy in pediatric patients: early and late results. Ann Thorac Surg. 2005;80:1424-30.

7. Dearani JA, Ommen SR, Gersh BJ, Schaff HV, Danielson GK. Surgery Insight: septal myectomy for obstructive hypertrophic cardiomyopathy-the Mayo Clinic experience. Nat Clin Pract Cardiovasc Med. 2007;4:503-12.

8. Altarabsheh SE, Dearani JA, Burkhart HM, Schaff HV, Deo SV, Eidem BW, et al. Outcome of septal myectomy for obstructive hypertrophic cardiomyopathy in children and young adults. Ann Thorac Surg. 2013;95:663-9.

9. Theodoro DA, Danielson GK, Feldt RH, Anderson BJ. Hypertrophic obstructive cardiomyopathy in pediatric patients: results of surgical treatment. J Thorac Cardiovasc Surg. 1996;112:1589-99.

10. Minakata K, Dearani JA, Schaff HV, O'Leary PW, Ommen SR, Danielson GK. Mechanisms for recurrent left ventricular outflow tract obstruction after septal myectomy for obstructive hypertrophic cardiomyopathy. Ann Thorac Surg. 2005;80:851-6.

11. Wilkinson JD, Lowe AM, Salbert BA, Sleeper LA, Colan SD, Cox GF, et al. Outcomes in children with Noonan syndrome and hypertrophic cardiomyopathy: a study from the pediatric cardiomyopathy registry. Am Heart J. 2012;164:442-8.

12. Alexander PMA, Nugent AW, Daubeney PEF, Lee KJ, Sleeper LA, Schuster T, et al. Long-term outcomes of hypertrophic cardiomyopathy diagnosed during childhood: results from a national population-based study. Circulation. 2018; 138:29-36.

13. Cooley DA, Garrett JR. Septoplasty for left ventricular outflow obstruction without aortic valve replacement: a new technique. Ann Thorac Surg. 1986;42: 445-8.

14. Bichell DP. Modified Konno procedure for left ventricular outflow tract obstruction. Oper Tech Thorac Cardiovasc Surg. 2011;16:62-9.

15. Vouhé PR. Valve-sparing Konno and hypertrophic obstructive cardiomyopathy in children. Oper Tech Thorac Cardiovasc Surg. 2014;19: 164-78.

16. Maron BJ, Spirito P, Ackerman MJ, Casey SA, Semsarian C, Estes NA III, et al. Prevention of sudden cardiac death with implantable cardioverter-defibrillators in children and adolescents with hypertrophic cardiomyopathy. J Am Coll Cardiol. 2013;61:1527-35.

17. Fucci C, Sandrelli L, Pardini A, Torracca L, Ferrari M, Alfieri O. Improved results with mitral valve repair using new surgical techniques. Eur J Cardiothorac Surg. 1995;9:621-7.

18. Walter EMBD, Siniawski H, Hetzer R. Sustained improvement after combined anterior mitral valve leaflet retention plasty and septal myectomy in preventing systolic anterior motion in hypertrophic obstructive cardiomyopathy in children. Eur J Cardiothorac Surg. 2009;36:546-52.

19. Subash Chandra V, Jayranganth M, Shenoy AR. Non-surgical septal reduction for hypertrophic cardiomyopathy in childhood. Int J Cardiol. 2006; 106:355-9.

20. Sreeram N, Emmel M, de Giovanni JV. Percutaneous radiofrequency septal reduction for hypertrophic obstructive cardiomyopathy in children. J Am Coll Cardiol. 2011;58:2501-10.

21. Gersh BJ, Maron BJ, Bonow RO, Dearani DA, Fifer MA, Link MS, et al. 2011 ACCF/AHA guideline for the diagnosis and treatment of hypertrophic cardiomyopathy: a report of the American College of Cardiology Foundation/American Heart Association task force on practice guidelines. Circulation. 2011;124:e783-831.

22. Ommen SR, Maron BJ, Olivotto I, Maron MS, Cecchi F, Betocchi S, et al. Long-term effects of surgical septal myectomy on survival in patients with obstructive hypertrophic cardiomyopathy. J Am Coll Cardiol. 2005;46:470-6.

23. Brown ML, Schaff HV, Dearani JA, Li Z, Nishimura RA, Ommen SR. Relationship between left ventricular mass, wall thickness, and survival after subaortic septal myectomy for hypertrophic obstructive cardiomyopathy. J Thorac Cardiovasc Surg. 2011;141:439-43.

24. Maron BJ, Spirito P, Wesley Y, Arce J. Development and progression of left ventricular hypertrophy in children with hypertrophic cardiomyopathy. N Engl J Med. 1986;315:610-4.

25. Quintana E, Johnson JN, Sabate Rotes A, Cetta F, Ommen SR, Schaff HV, et al. Surgery for biventricular obstruction in hypertrophic cardiomyopathy in children and young adults: technique and outcomes. Eur J Cardiothorac Surg. 2015;47: 1006-12.

26. Hirsch HD, Gelband H, Garcia O, Gottlieb S, Tamer DM. Rapidly progressive obstructive cardiomyopathy in infants with Noonan's syndrome. Report of two cases. Circulation. 1975;52:1161-5.

27. Poterucha JT, Johnson JN, O’Leary PW, Connoly HM, Niaz T, Maleszewski JJ, et al. Surgical ventricular septal myectomy for patients with Noonan syndrome and symptomatic left ventricular outflow tract obstruction. Am J Cardiol. 2015;116:1116-21.

28. Gelb BD, Roberts AE, Tartaglia M. Cardiomyopathies in Noonan syndrome and the other RASopathies. Prog Pediatr Cardiol. 2015;39:13-9.

29. Biagini E, Spirito P, Rocchi G, Ferlito M, Rosmini S, Lai F, et al. Prognostic implications of the Doppler restrictive filling pattern in hypertrophic cardiomyopathy. Am J Cardiol. 2009;104:1727-31.

30. Monteiro PF, Ommen SR, Gersh BJ, Darani JA, Schaff HV, Nishimura RA, et al. Effects of surgical septal myectomy on left ventricular wall thickness and diastolic filling. Am J Cardiol. 2007;100:1776-8.

31. Moravsky G, Bruchal-Garbicz B, Jamorski M, Ralph-Edwards A, Gruner C, Williams L, et al. Myocardial mechanical remodeling after septal myectomy for severe obstructive hypertrophic cardiomyopathy. J Am Soc Echocardiogr. 2013;26:893-900.

Key Words: hypertrophic cardiomyopathy, implantable cardioverter-defibrillator, Noonan syndrome, pediatrics, right ventricular outflow tract obstruction, septal myectomy 
TABLE E1. The $95 \%$ confidence intervals for time-dependent figures

\begin{tabular}{|c|c|c|c|c|c|}
\hline Percent survival $(95 \%$ CI $)$ & $1 \mathbf{y}$ & $5 y$ & $10 y$ & $15 y$ & $20 y$ \\
\hline Figure 2, $A$ & 100 & $95.8(84.1-98.9)$ & $95.8(84.1-98.9)$ & $82.3(94.7-49.9)$ & $82.3(94.7-49.9)$ \\
\hline \multicolumn{6}{|l|}{ Figure $2, B$} \\
\hline Nonsyndromic HCM & $97.8(85.6-99.5)$ & $94.8(80.3-98.6)$ & $84(60-94.2)$ & $67.2(26.7-88.7)$ & $67.2(26.7-88.7)$ \\
\hline NS & $75(50-88.5)$ & $69.6(44.4-85)$ & $69.6(44.4-85)$ & $69.6(44.4-85)$ & $69.6(44.4-85)$ \\
\hline \multicolumn{6}{|l|}{ Figure $3, A$} \\
\hline$<25 \mathrm{~mm}$ & 100 & $96.8(79.2-99.4)$ & $96.8(79.2-99.4)$ & $82.9(37.7-96.5)$ & $82.9(37.7-96.5)$ \\
\hline$\geq 25 \mathrm{~mm}$ & 100 & $79.1(52.9-91.7)$ & $60.3(29.5-87.1)$ & $40.2(29.5-87.1)$ & $40.2(29.5-87.1)$ \\
\hline \multicolumn{6}{|l|}{ Figure $3, B$} \\
\hline No & 100 & $94.5(80.5-98.5)$ & $85.2(63.5-94.5)$ & $76.7(48.6-90.7)$ & 76.7 (48.6-90.7) \\
\hline Yes & 100 & $71.6(35.1-89.9)$ & $71.6(35.1-89.9)$ & $35.8(1.8-77.6)$ & $35.8(1.8-77.6)$ \\
\hline
\end{tabular}

CI, Confidence interval; $H C M$, hypertrophic cardiomyopathy; NS, Noonan syndrome.

TABLE E2. Comparison of patients with Noonan syndrome and nonsyndromic hypertrophic cardiomyopathy

\begin{tabular}{|c|c|c|c|}
\hline Characteristics & NS $(n=20)$ & Nonsyndromic HCM $(n=53)$ & $P$ value \\
\hline Antenatal diagnosis & $1(5)$ & $4(7)$ & $\mathrm{ns}$ \\
\hline Age at diagnosis & $0.4 \pm 0.75$ & $3.6 \pm 4.7$ & .01 \\
\hline Resuscitated SCD & 0 & $4(7)$ & - \\
\hline Previous defibrillator implantation & $1(5)$ & $3(6)$ & ns \\
\hline Pulmonary valve stenosis & $11(58)$ & $1(2)$ & $<.0001$ \\
\hline NYHA class III-IV & $7(37)$ & $32(59)$ & .11 \\
\hline Angina pectoris & $2(10)$ & $16(30)$ & $\mathrm{ns}$ \\
\hline Syncope & $1(5)$ & $2(4)$ & ns \\
\hline Congestive heart failure & $3(16)$ & $2(4)$ & ns \\
\hline Beta-blocker therapy & $16(84)$ & $48(89)$ & $\mathrm{ns}$ \\
\hline Maximal septal thickness (mm) & $20 \pm 7.5$ & $23.6 \pm 7.2$ & ns \\
\hline Maximal septal thickness z-score & $12.3 \pm 7.2$ & $16 \pm 7.5$ & $\mathrm{~ns}$ \\
\hline Right ventricle involvement & $12(60)$ & $11(20)$ & .004 \\
\hline Maximal LVOT gradient $(\mathrm{mm} \mathrm{Hg})$ & $105 \pm 7$ & $95 \pm 7$ & .4 \\
\hline Maximal LVOT velocity $(\mathrm{m} / \mathrm{s})$ & $5.2 \pm 0.8$ & $4.7 \pm 1.3$ & .2 \\
\hline Maximal RVOT gradient (mm Hg) & $80(2-88)$ & $15.5(2-75)$ & .06 \\
\hline RVOT obstruction & $11(55)$ & $9(17)$ & .002 \\
\hline Mitral valve dysplasia & $5(26)$ & $4(7)$ & .04 \\
\hline Anomalous subvalvular mitral apparatus & $3(16)$ & $14(26)$ & ns \\
\hline \multicolumn{4}{|l|}{ Mitral regurgitation } \\
\hline Mild & $4(21)$ & $16(30)$ & $\mathrm{ns}$ \\
\hline Moderate & $2(11)$ & $10(19)$ & $\mathrm{ns}$ \\
\hline Severe & 0 & $2(4)$ & - \\
\hline \multicolumn{4}{|l|}{ Aortic regurgitation } \\
\hline Mild & 0 & $2(4)$ & - \\
\hline Moderate & 0 & $1(2)$ & - \\
\hline \multicolumn{4}{|l|}{ Procedure } \\
\hline Age at surgery & $3.3(0.1-18.8)$ & $8.6(0.3-19.1)$ & .03 \\
\hline Weight & $10.8(3.63-49)$ & $29.6(5-92)$ & .003 \\
\hline Body surface $\left(\mathrm{m}^{2}\right)$ & $0.74 \pm 0.5$ & $1.14 \pm 0.4$ & .01 \\
\hline Associated procedure & $7(37)$ & $12(23)$ & $\mathrm{ns}$ \\
\hline
\end{tabular}

Data are n (\%), median (range), or mean \pm SD. NS, Noonan syndrome; HCM, hypertrophic cardiomyopathy; $n s$, not significant; $S C D$, sudden cardiac death; $N Y H A$, New York Heart Association; $L V O T$, left ventricular outflow tract; RVOT, right ventricular outflow tract. 
TABLE E3. Determinants of primary prevention implantable cardioverter-defibrillator implantation and implantable cardioverter-defibrillatorrelated outcomes in children undergoing operation after 2010

\begin{tabular}{|c|c|c|c|}
\hline Primary prevention ICD implantation & Yes $(\mathbf{n}=20)$ & No $(n=13)$ & $P$ value \\
\hline Age at procedure & $13.8(9.6-18.8)$ & $4.3(0.3-14.8)$ & .003 \\
\hline First-degree family history of SCD & 5 & 0 & - \\
\hline Septal thickness z-score & $25 \pm 5$ & $12 \pm 6$ & .0008 \\
\hline Maximum transaortic gradient & $107 \pm 47$ & $91 \pm 30$ & ns \\
\hline Syncope or malaise & 4 & 3 & ns \\
\hline Abnormal exercise AP profile & $7 / 11$ & $4 / 4$ & ns \\
\hline Ventricular tachycardia on Holter-monitor & $3 / 7$ & $1 / 6$ & ns \\
\hline \multicolumn{4}{|l|}{ Outcomes } \\
\hline Patients with appropriate shocks & 1 & - & - \\
\hline Patients with inappropriate shocks & 0 & - & - \\
\hline Resuscitated VF & - & 1 & - \\
\hline
\end{tabular}

Data are n (\%), median (range) or mean \pm SD. $I C D$, Implantable cardioverter-defibrillator; $S C D$, sudden cardiac death; $n s$, not significant; $A P$, arterial pressure; $V F$, ventricular fibrillation. 